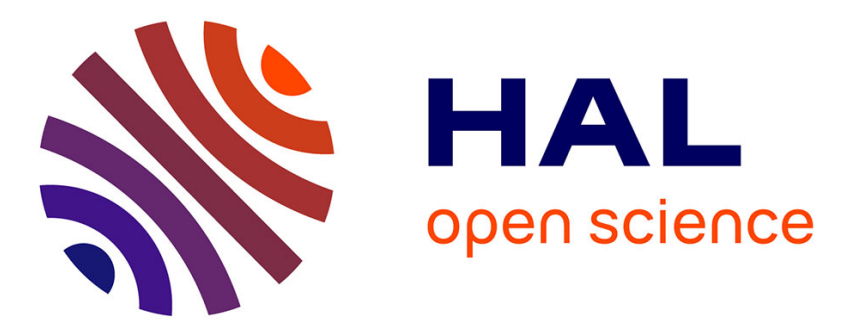

\title{
Celiac Disease and Obesity: Is Bariatric Surgery an Option?
}

Manon Lojou, Nicolas Sahakian, Anne Dutour, Geoffroy Vanbiervliet, Thierry Bege, Benedicte Gaborit

\section{- To cite this version:}

Manon Lojou, Nicolas Sahakian, Anne Dutour, Geoffroy Vanbiervliet, Thierry Bege, et al.. Celiac Disease and Obesity: Is Bariatric Surgery an Option?. Obesity Surgery, 2020, 30 (7), pp.2791-2799. 10.1007/s11695-020-04607-z . hal-03158851

\section{HAL Id: hal-03158851 https://hal.inrae.fr/hal-03158851}

Submitted on 16 Mar 2021

HAL is a multi-disciplinary open access archive for the deposit and dissemination of scientific research documents, whether they are published or not. The documents may come from teaching and research institutions in France or abroad, or from public or private research centers.
L'archive ouverte pluridisciplinaire HAL, est destinée au dépôt et à la diffusion de documents scientifiques de niveau recherche, publiés ou non, émanant des établissements d'enseignement et de recherche français ou étrangers, des laboratoires publics ou privés. 


\section{CELIAC DISEASE AND OBESITY: IS BARIATRIC SURGERY AN OPTION?}

Lojou $\mathbf{M}^{1}$, M.D., Sahakian $\mathbf{N}^{1}$, M.D., Dutour A ${ }^{1,2}$, M.D., Ph.D, Vanbiervliet $G^{3}$ M.D., Ph.D, Bege $T^{4,5}$ M.D., Ph.D, Gaborit B ${ }^{1,2}$ M.D., Ph.D.

51 Department of Endocrinology, Metabolic disease and Nutrition, Assistance Publique-Hôpitaux de Marseille, France

${ }^{2}$ Aix-Marseille University, INSERM, INRAE, C2VN, Marseille, France

${ }^{3}$ Digestive Medicine, L’Archet 2 University Hospital-Nice, France

${ }^{4}$ Department of Digestive Surgery, Hôpital Nord, Aix-Marseille University, Chemin des

10 Bourrely, 13915 Marseille Cedex 20, France

${ }^{5}$ Aix-Marseille University, IFSTTAR, LBA, Marseille, France

Corresponding author:

Bénédicte Gaborit: Department of Endocrinology, Metabolic Disease and Nutrition, 15 Pole ENDO, Hôpital Nord, Chemin des Bourrely, 13915 Marseille Cedex 20, France. Phone: +33 49196 8823; Fax: +33 49196 8878; Email: Benedicte.GABORIT@ap-hm.fr 


\section{Abstract}

20 Celiac disease (CD) is an immune-mediated enteropathy associated with malabsorptive syndrome and fat-soluble vitamin deficiencies. $\mathrm{CD}$ affects one percent of individuals but is largely underdiagnosed, as its multifaceted clinical presentations create challenging diagnostic scenarios. With the rise of the obesity epidemic, doctors are increasingly seeing CD patients with overweight or obesity, which raises the question of bariatric surgery. However, few studies so far have investigated bariatric surgery in this patient population. Here we provide a comprehensive review of the literature on $\mathrm{CD}$, its nutritional consequences and complications, and we discuss the possible impact of bariatric surgery on weight loss, nutritional deficiencies, response to gluten-free diet, and long-term post-operative complications. We also review the effect of bariatric surgery on the incidence of $\mathrm{CD}$.

Keywords: Celiac disease, bariatric surgery, obesity, gluten-free diet, Roux-en-Y bypass, sleeve gastrectomy 


\section{Introduction}

35 Celiac disease (CD) is an autoimmune disorder that can occur in genetically predisposed people where the ingestion of gluten leads to damage in small intestine[1]. It is characterized by villous atrophy inducing a malabsorption syndrome [2]. CD was classically defined in the child as a chronic enteropathy with villous atrophy secondary to an inappropriate immune response of the intestinal mucosa to the gliadin in wheat, barley and rye. The disorder often presents with diarrhea, malabsorption of one or more nutrients, and resultant weight loss, and it involves a mucosal inflammatory response that extends from the duodenum into the more distal small intestine for variable distances.

$\mathrm{CD}$ is heavily underdiagnosed, due to its many variable clinical symptoms and multi-organ manifestations (Figure 1). Diagnosis of CD is based on the presence of predisposing genetic factor human leukocyte antigen (HLA) DQ2/8 haplotypes, with positive small intestine biopsy and serological antibodies upon a gluten-containing diet[3]. Histological confirmation of $\mathrm{CD}$ diagnosis is based on demonstrated small bowel mucosal villous atrophy, intraepithelial lymphocytosis and crypt hyperplasia in biopsy samples obtained by gastroscopy $[4,5]$.

The spectrum of CD may present in different forms. The classical form may be diagnosed at any age of life and is often characterized by crypt hyperplasia and villous atrophy along with features of malabsorption [1,6]. Diarrhea, steatorrhea, weight loss or growth failure is required. The atypical form is characterized by positive celiac serology, limited abnormalities of the small intestinal mucosa or no intestinal symptoms, but associated extraintestinal conditions such as osteoporosis, peripheral neuropathy, anemia and infertility. The latent form is defined by presence of predisposing gene HLADQ2 and/or HLA-DQ8, normal intestinal mucosa and, possible positive serology [3]. This changing face of CD (more latent than 
classical form) is accompanied by a change in diagnostic strategies but also in the whole definition of the disease itself [7].

60 Historically, patients with CD were more frequently underweight, but nowadays CD patients are increasingly overweight or obese [8,9]. Some who are severely obese are candidates for bariatric surgical management. Bariatric surgery is generally safe, feasible and effective in patients with autoimmune disorders $[10,11]$. However, in certain types of surgery, co-existing malabsorptive processes may further increase the risk of post-operative complications or nutritional deficiencies. This review provides a thorough appraisal of CD in the context of obesity, its nutritional consequences and complications, and opens discussion on the possible impact of bariatric surgery on weight loss, nutritional deficiencies, response to gluten-free diet, and long-term post-operative complications.

\section{Epidemiology of celiac disease}

70 The prevalence of CD has increased significantly over the past fifty years, partly due to better diagnostic tools and screening of individuals at high risk for the disorder [2]. In Western countries, the prevalence of $\mathrm{CD}$ is between 0.6 and $1 \%$ in the general population, but a much more prevalent $3-6 \%$ in type 1 diabetics, $5-10 \%$ in the first-degree relatives of a CD patient, from 1 to $3 \%$ in osteoporotic patients and from $3 \%$ to $15 \%$ in patients with iron-deficiency anemia [12]. The prevalence of CD varies according to ethnic origin. It is high in Caucasians compared to Blacks and Hispanics, which appears to correlate with the frequency of patients with a predisposing HLA gene. The prevalence of CD in European countries was found to be 1\% (among 29,212 patients from Finland, Germany, Italy and the UK). Incidences close to those of Europe or the United States were noted in North Africa, the Middle East and India. On the other hand, CD is almost unseen in Southeast Asia and Black Africa. 
Note that $30 \%$ of Caucasian populations carry HLA-DQ2, and most will eat wheat, while only 1 in 100 will develop the disease. The remaining susceptibility is thought to be due to a combination of genetic and environmental factors [3]. Overall, the HLA-DQ2 haplotype confers the highest genetic risk for developing $\mathrm{CD}$. There is also a general consensus that female gender and a family history of CD are also risk factors. In a recent publication, higher gluten intake during the first 5 years of life was associated with increased risk of CD autoimmunity and CD among genetically predisposed children carrying HLA antigen genotypes associated with type 1 diabetes and CD [13].

90 The incidence of $\mathrm{CD}$ has increased significantly over the last 30 years, from 2-3 to 9 or 13 new cases per 100,000 inhabitants per year [14-16]. This increase in incidence over time probably reflects more recognition of atypical and latent forms through serological testing. Differences in the prevalence of predisposition genes and food diversification practices (gluten introduced earlier or later in life) could also explain the geographical variations andover time-incidence of the disease. However, the majority of patients with $\mathrm{CD}$ remain undetected worldwide, and several reports have suggested that upper gastrointestinal surgeries may unmask undiagnosed CD [2].

\section{Nutritional consequences of celiac disease}

There are two types of intestinal mucosal damage: first a reduction in the number of mature absorptive cells, and second a dysfunction of the remaining cells characterized by villous atrophy (flattening of the mucosa and reduction of the absorptive surface).

Reduced levels of iron, folate, vitamin B12, vitamin D, zinc and magnesium are common in untreated CD patients, probably due to a loss of brush border proteins and enzymes needed for the absorption of these nutrients. In a majority of patients, removing gluten from the diet 
105 leads to histological recovery and normalization of iron, vitamin and mineral levels. Irondeficiency anemia is the most common extra-intestinal sign of CD and usually resolves with adherence to a gluten-free diet. However, deficiencies of both folate and vitamin B12 may persist in some patients on a gluten-free diet, thus requiring vitamin supplementation to improve health status. Similarly, bone mineral density does not always normalize after

110 excluding gluten from the diet, and in these cases vitamin D and calcium supplementation is recommended. Furthermore, resolution of mucosal inflammation may not be enough to abrogate magnesium deficiency. Since gluten-free cereal products have a lower magnesium content than their gluten-containing counterparts, a magnesium-enriched diet should be encouraged in CD patients [17]. Table 1 summarizes the nutritional deficiencies frequently 115 reported with a gluten-free diet (GFD) [18-21].

In a study of 80 patients assessing the nutritional and vitamin/mineral status of current 'early diagnosed' but untreated adult CD patients in the Netherlands, Wierdsma et al.[22] showed that compared to healthy individuals, $\mathrm{CD}$ patients were most frequently deficient in folic acid (20\%, 16/80), followed by vitamin B12 (19\%, 15/79), vitamin B6 (14.5\%, 9/62), vitamin A $(7.5 \%, 4 / 53)$ and vitamin (25-hydroxy) D (4.5\%, 1/21). Approximately 67\% (26/39) of the patients had zinc deficiency, 32.4\% (23/71) had anemia, 46.2\% (18/39) had insufficient iron stores evidenced by low ferritin, and 25\% (8/40) had iron-deficiency anemia. CD patients had lower vitamin A and folic acid than healthy controls. Overall, 17\% were malnourished (>10\% undesired weight loss), $22 \%$ of the women were underweight $(\mathrm{BMI}<18.5)$, and $29 \%$ of all 125 patients were overweight $(\mathrm{BMI}>25)$. Vitamin deficiencies were barely seen in healthy controls, with the exception of vitamin B deficiency [22].

In a study of 39 biopsy-proven CD patients, $16(41 \%)$ patients were vitamin B12-deficient $(<220 \mathrm{ng} / \mathrm{L})$ and $16(41 \%)$ patients (11 women and five men) were anemic [18]. Only 5/16 (31\%) of the vitamin B12-deficient patients were also folate-deficient. The Schilling test, 
130 performed in 10 of the vitamin B12-deficient patients, showed five low and five normal results. Although only five patients received parenteral vitamin B12, the vitamin B12 levels had normalized in all patients at follow-up. Three vitamin B12-deficient patients had acral paresthesia at presentation that resolved after vitamin B12 replacement [18].

A well-led gluten-free diet will correct most vitamin and trace element deficits.

135 Deora et al.[23] evaluated the prevalence of micronutrient deficiencies in 140 CD patients under 17 years old and measured serum micronutrient levels and IgA-class antitransglutaminase antibodies at diagnosis, 6 months and 18 months after starting a GFD. At diagnosis, serum vitamin D was the most commonly deficient vitamin in $70 \%$ of children. Serum ferritin was subnormal in $34.5 \%$ along with zinc in $18.6 \%$ of children, and remarkably,

140 only $12(10.9 \%)$ children had iron-deficiency anemia. There was no correlation between micronutrient deficiencies at diagnosis and serum transglutaminase IgA antibody or degree of villous atrophy. Reassuringly, the measured serum micronutrient levels had mostly normalized at 6 months after starting GFD, except for vitamin D which improved but remained subnormal [23].

145 Nevertheless, the GFD remains a difficult diet to follow, with compliance problems, that may lead to the exclusion of certain foods and therefore other nutritional deficiencies. CD is a lifelong disorder, and effective treatment with a strict GFD is difficult and usually timeconsuming for the patient.

\section{Severe complications of celiac disease}

150 The two main serious and feared complications of CD are intestinal lymphoma and small bowel adenocarcinoma [1,2].

Lymphoma complications of $\mathrm{CD}$ are rare, with an incidence of less than 3 per 100,000 inhabitants per year, but serious. One identified lymphoma complication is clonal refractory 
sprue, known as type II (SR II). SR II is an intra-epithelial lymphoma with a low degree of 155 malignancy that is associated with $\mathrm{CD}$ and characterized by an expansion of small intraepithelial lymphocytes of abnormal phenotype. It's course can evolve into highmalignancy T-lymphoma in 30 to $50 \%$ of cases at 5 years, and its prognosis is bleak, with less than $45 \%$ of patients alive 5 years after diagnosis [24,25]. Diagnosis is difficult and requires specific immunohistochemical, phenotyping and molecular studies. Emerging from the small

160 intestine, the abnormal intraepithelial lymphocytes can spread through the entire digestive tract (distal small intestine, stomach, and colon), circulate in the blood, and invade the bone marrow and various epithelia such as the epitheliotropic skin and lungs. More recently, granular leukemias (like large granular lymphocytic leukemia) have been identified which, from the periphery, invade the intestine of CD patients, often leading to GFD resistance.

165 These high-malignancy T-lymphomas (enteropathy-associated T-lymphoma; EATL) are rare (incidence estimated between 0.22 and 1.9 per 100,000 inhabitants) but with a bleak outcome. EATL may be diagnosed through surgery revealing $\mathrm{CD}$, but when $\mathrm{CD}$ is already diagnosed, it is important to screen for lymphoma in case of resistance to GFD, whereas diagnosis after roux-en-Y gastric bypass (RYGB) can prove complex due to the excluded jejunum.

There is a reported increase in the risk of small bowel adenocarcinoma in patients with CD (odds ratio ranges between 4.3 to 60.0 ) that is usually detectable in the jejunum [26]. Indeed, in a study that evaluated the frequency of small-bowel malignancy in the UK and its relationship to the presence of $\mathrm{CD}$, the authors found a diagnosis of $\mathrm{CD}$ in $13 \%$ of 175 adenocarcinoma cases and in $39 \%$ of lymphomas, which highlights the fact that CD confers susceptibility to small bowel adenocarcinoma as well as lymphoma [27]. Unlike intestinal lymphoma, small bowel adenocarcinoma is not preceded by refractory CD and should be suspected in cases of sudden intestinal (sub)occlusion and/or anemia [1]. In their retrospective 
study, Sharma et al. found no increase in intestinal lymphoma $(\mathrm{p}=0.99)$ nor an increase in

180 small intestine adenocarcinoma in CD patients given bariatric surgery [28].

\section{Prevalence of obesity in celiac disease and effect of gluten-free diet on weight}

The worldwide surge in number of obese individuals is also increasing the number of CD patients who are overweight or obese. CD had historically been diagnosed in underweight patients, but the trends seem to be reversing. Overall, the majority of $\mathrm{CD}$ patients have a normal BMI: the prevalence of underweight varies from $3 \%$ to $36 \%$, and the prevalence of overweight and obesity varies from $6 \%$ to $39 \%$ and from $3 \%$ to $13 \%$, respectively [29-33]. Table 2 summarizes the prevalence of underweight, normal, overweight, and obese patients among patients with $\mathrm{CD}$. Comparative analysis versus general population data found that $\mathrm{CD}$ women had a significantly lower BMI $\left(21.9\right.$ vs $\left.24.2 \mathrm{~kg} / \mathrm{m}^{2}, \mathrm{p}<0.0001\right)$ and fewer of them were overweight (11\% vs 21\%, p<0.0001). More CD men had normal BMI $(59.5 \%$ vs 34\%, $\mathrm{p}$ $<0.0001)$, and fewer CD men were underweight $(9.1 \%$ vs $26.7 \%, \mathrm{p}<0.0001)$.

After 2.8 years of well-monitored GFD), $66 \%$ of underweight patients gained weight, while $54 \%$ of overweight patients and $47 \%$ of obese patients lost weight [31].

195 Many studies have found weight loss or stable weight in overweight or obese CD patients under a well-conducted GFD [21,29,31,34]. Ukkola et al. [32] prospectively investigated weight and disease-related issues in 698 newly-detected CD adults at diagnosis and after one year on a GFD and compared the findings with figures for the general population. At diagnosis, $4 \%$ of subjects were underweight, $57 \%$ normal, $28 \%$ overweight and $11 \%$ obese.

On a GFD, $69 \%$ of underweight patients gained weight and $18 \%$ of overweight and $42 \%$ of obese lost weight; in the rest, BMI remained stable. Changes were similar in both symptomand screen-detected patients (23). Another team compared BMI at diagnosis and after 2 years of treatment in patients with serological support for dietary compliance. Of GFD-compliant 
patients, $81 \%$ had gained weight after 2 years, including $82 \%$ of initially overweight patients

205 [29]. In a study on more than 1000 patients over three years, $22 \%$ of GFD-compliant patients gained weight, increasing their BMI by $>2$ pts [34]. Interestingly, when overweight or obese children adhere to a GFD, they may actually improve or normalize their BMI, whereas children of normal weight at the time of diagnosis are seemingly at risk for becoming overweight when starting a GFD [35]. Table 3 recaps the effect of GFD on weight gain or

210 loss in adults, as reported to date.

\section{Bariatric surgery and celiac disease}

\section{Bariatric surgery}

Bariatric surgery (BS) is currently the most effective treatment for severe obesity. It has developed exponentially in industrialized countries as it enables sustained weight loss, improves comorbidities, and reduces cardiovascular and general mortality [36]. A recent large database study found that sleeve gastrectomy (SG) accounted for 63\% of procedures performed, compared to $30 \%$ for Roux-en-Y gastric bypass (RYGB) and just $2 \%$ for laparoscopic adjustable gastric banding (LAGB) [37]. However, it also has side effects including nutritional deficiencies. Some of these deficiencies have demonstrated clinical impact that is sometimes severe, such as neurological complications due to vitamin B12 or B1 deficiency, iron-deficiency anemia, and bone demineralization with risk of fracture due to vitamin $\mathrm{D}$ and/or calcium deficiency.

There is growing consensus that BS leads to effective weight loss depending on type of surgery performed. Weight loss can reach up to $40 \%$ of initial weight and increases with malabsorptive procedures [38]. Percentage of excess weight loss varies from $47 \%$ for LAGB to more than $60 \%$ with RYGB and $70 \%$ for biliopancreatic diversion or duodenal switch [39]. 
Patients who undergo BS are monitored by a multidisciplinary team that is especially attentive to early and late complications. Restrictive and/or malabsorptive interventions frequently cause nutritional deficiencies. The main origins of these deficiencies are a lack of digestive assimilation and a lack of dietary intake due to drastic reduction of caloric intake, and possible intolerance to certain foods (fibers, proteins). The main nutritional deficiencies following BS concern proteins and certain functional amino acids, iron, zinc, calcium, vitamin D and other liposoluble vitamins, folate, vitamin B12, and polyunsaturated fatty acids $235[40]$

The American Society for Metabolic and Bariatric Surgery Integrated Health has updated its 'nutritional guidelines for the surgical weight loss patient on micronutrients' [38,41]. According to these guidelines, all types of surgery should systematically require thiamin, vitamin B12, folate, iron, calcium and vitamin D supplementation. Vitamin D deficiency is reported to occur in up to $100 \%$ of post-weight-loss surgery patients and folate deficiency in up to $65 \%$. These guidelines also state that the prevalence of micronutrient deficiencies is increasing while patient monitoring at follow-up is decreasing, thus justifying a multidisciplinary approach and life-long follow-up. In the Practical Recommendations of the Obesity Management Task Force of the European Association for the Study of Obesity for post-bariatric surgery medical management, Busetto et al. [42] state that long-term mineral and multivitamin supplementation should be prescribed to every bariatric patient with medication doses adapted to the procedure. Periodic laboratory surveillance for nutritional deficiencies is recommended and supplementation should be individualized accordingly in patients with demonstrated micronutrient deficiencies [42]. While nutritional deficiencies are uncommon after purely gastric restrictive procedures not altering intestinal continuity, they become very common after surgical procedures inducing malabsorption. However, the 
occurrence of nutritional deficits is also influenced by factors independent of surgical technique, such as regular and nutrient-dense food intake and adherence with post-operative vitamin and mineral supplementation, which is far from guaranteed.

\section{Celiac disease and bariatric surgery: reported outcomes and response to gluten-free diet}

CD patients who fail to properly adhere to the GFD are exposed to a panel of vitamin deficiencies due to malabsorption syndrome. However, BS, and especially gastric bypass, also increases the risk of deficiencies.

The literature suggests that BS is safe and feasible in patients with concomitant autoimmune, inflammatory and intestinal pathologies including systemic lupus erythematosus and inflammatory bowel disease $[10,11]$. However, the role of BS in obese CD patients is less well defined. Combining a malabsorptive state such as $\mathrm{CD}$ with a restrictive and/or additional malabsorptive procedure may further increase the risk of post-operative complications or nutritional deficiencies.

Does the risk of malnutrition and complications secondary to vitamin deficiency compromise surgery? Should patients with CD be offered a purely restrictive bariatric procedure, as some have suggested?

270 The prevalence of $\mathrm{CD}$ in $\mathrm{BS}$ populations is relatively low, and few $\mathrm{CD}$ patients have undergone BS [28,43]. A study retrospectively reviewed 12,000 RYGB patients for either diagnosis (American Gastroenterological Association diagnostic criteria) or serum testing for CD [43]. Of these 12,000 patients, 342 had abnormal serology, only 3 patients $(0.8 \%)$ were confirmed with CD diagnosed before the procedure, and only two followed a GFD. All were

275 female, with an average age of 33 years and a mean BMI of $44.07 \mathrm{~kg} / \mathrm{m}^{2}$. Interestingly, there was no significant difference in terms of weight loss or excess weight loss between CD and 
non-CD bariatric patients. No patients were anemic nor had vitamin B12 or iron deficiencies at 12-month follow-up. However, two patients had vitamin D insufficiencies that responded to daily oral supplementation [43]. In a nationwide inpatient sample analysis between 2004 and 2014, Sharma et al. [28] identified 126 patients with CD that had undergone bariatric surgery. BS did not increase in mortality, but CD patients with obesity and prior BS were three times more likely to have vitamin D deficiency (IRR 3.5; 95\%CI $1.6-7.7 ; \mathrm{p}=0.002$ ) or post-operative strictures (IRR 3.3; 95\%CI 1.5-7.5; $\mathrm{p}=0.004)[28]$.

The effect of GFD on weight (in patients who benefited from BS) is a hugely controversial topic. Some teams consider that it leads to weight gain in obese patients. An Italian team reported the case of a patient incidentally diagnosed with the silent form of CD 5 years after BS and who had changed his BMI from 35.2 to 38.4 after 12 months of GFD [44]. Their paper reports complete restoration of the intestinal mucosa within 12 months after starting GFD after BS (vertical banded gastroplasty) had been performed 5 years earlier [44].

290 On the other hand, cases where symptoms persist despite a well-followed GFD are defined as refractory sprue, which is a condition that leads to a risk of T-cell lymphoma (EATL) requiring endoscopic monitoring with duodenojejunal biopsies [25]. However, the realization of a gastric bypass would result in a more difficult endoscopic follow-up in these patients[45].

Moreover, it is difficult to differentiate the usual post-surgery digestive symptoms from the 295 persistence of symptoms related to a refractory disease like diarrhea.

As recommended by The American College of Gastroenterology [14] and the European Society for the Study of Coeliac Disease [2] recommend testing for CD in certain settings, especially before BS: 
- Patients with symptoms, signs or laboratory evidence suggestive of malabsorption, such as chronic diarrhea with weight loss, steatorrhea, postprandial abdominal pain and bloating, or elevated serum aminotransferase levels when no other etiology is found

- Patients with a first-degree relative who has a confirmed diagnosis of CD should be tested - Patients with type 1 diabetes mellitus should be screened regularly for CD, notably if there are any digestive symptoms, or signs or laboratory evidence suggestive of CD.

305 Diarrhea is classically predominant in $\mathrm{CD}$, but CD should be part of the differential diagnosis in cases of post-BS diarrhea so as not to misread a diagnosis.

\section{Is there increased incidence of $\mathrm{CD}$ after bariatric surgery?}

A recent study reported the first case of CD diagnosed in the follow-up of duodenal switch in a woman with severe diarrhea shortly after surgery. Final diagnosis was later made based on anti-transglutaminase antibodies. The authors suggest that CD should be ruled out in patients with typical or atypical symptoms after BS regardless of the latency of onset [46]. Another asymptomatic case reported after vertical banded gastroplasty was due to familial history [44]. The mechanism by which BS can unmask latent CD is still unknown. It is thought that transient bowel hyperpermeability following such procedures could lead to an antigenic overload, but altered nutrient absorption, motility, perioperative stress and hormone variations could also be implicated [2]. In susceptible patients, the heightened gluten challenge might then sufficiently stimulate the immune response to result in clinically apparent enteropathy [47].

\section{Discussion}

CD has traditionally been associated with malabsorption and insufficient body weight, but approximately $10 \%$ of CD patients are obese at diagnosis. They could, therefore, be potential 
candidates for BS. With the current obesity epidemic and the increasing incidence of CD, this

325 situation is set to become more frequent in the near future, which raises issues concerning the specific diagnosis, choice of bariatric procedure, and specific follow-up or complications. If a malabsorptive procedure is decided, it may add to the complexity of diagnosing CD complications. Furthermore, starting a GFD after BS could increase the risk of weight regain, and so weight maintenance counselling should be an integral part of celiac dietary 330 education[34]. In addition, many processed gluten-free products have an increased glycemic index with increased fat and lower proteins than gluten-containing meals, which raises the challenge of achieving sufficient protein intake post-operatively $[2,38]$.

Several teams have suggested a preoperative work-up of specific CD tests (anti-endomysial and anti-transglutaminase antibodies and total $\operatorname{IgA}$ ) before bariatric procedures. After malabsorptive surgery, diagnosis of CD by duodenal biopsies during endoscopy is technically more difficult in non-expert centers due to the excluded jejunum. In these cases, testing exclusively by serology remains an option. Indeed, a negative CD-specific serology does not completely rule out a diagnosis of $\mathrm{CD}$, though it does make it much less likely.

The standard treatment of CD implementing a GFD is also successful in BS patients. 340 However, apart from a few case reports, little is known about onset, course, diagnosis and management of CD following BS, particularly after sleeve gastrectomy and RYGB.

Should this type of surgery be indicated in patients with CD, including gastric bypass?

Should patients be screened pre-operatively in order to not miss the diagnosis and avoid the increased risk of malabsorption deficiencies? Figure 1 recaps the clinical manifestations of $345 \mathrm{CD}$ and the possible impact of BS on this protein-losing enteropathy.

This was argued in a recent study that reported 5 cases of patients diagnosed preoperatively. Four of them were asymptomatic and one had chronic diarrhea and anemia. Three of them 
underwent sleeve gastrectomy. The authors suggest that, given the increasing number of asymptomatic obese patients with $\mathrm{CD}$, all patients should be screened preoperatively to adapt the surgical strategy accordingly [48]. The authoritative international societies have not yet defined a specific surgical strategy according to $\mathrm{CD}$ screening results.

To sum up, the literature and the experience of leading groups converge to show that $\mathrm{BS}$ is possible and clearly an option in severe obese patients with $\mathrm{CD}$ as long as they are compliant with the GFD and do not have preoperative vitamin deficiencies. However, multidisciplinary teams should carry out strengthened monitoring of vitamin status and protein intake and better frame the management of weight loss.

Based on the current state of the art, systematic preoperative screening for $\mathrm{CD}$ in bariatric patients cannot be recommended as it carries a cost and CD in BS is still rare. Nevertheless, it should be part of the conversation with genetically-predisposed patients such as type 1 diabetics or patients with a family history of CD. More extensive studies in large populations with long-term follow-up are now needed to definitively answer these questions.

\section{Conclusion}

365 Currently, almost $10 \%$ of celiac patients are obese at diagnosis, and could therefore be potential candidates for BS depending on their BMI and comorbidities. In addition, in the case of latent $\mathrm{CD}$, symptoms may be precipitated by gastrointestinal aggression such as BS. The issues of whether potential bariatric patients should systematically be screened for CD before surgery and whether the diagnosis of $\mathrm{CD}$ would influence the type of procedure merit further evaluation. 


\section{Conflicts of interest}

The authors declare that they have no conflicts of interest. 
1. Caio G, Volta U, Sapone A, Leffler DA, De Giorgio R, Catassi C, et al. Celiac disease: a comprehensive current review. BMC Med. 2019;17:142.

2. Al-Toma A, Volta U, Auricchio R, Castillejo G, Sanders DS, Cellier C, et al. European Society for the Study of Coeliac Disease (ESsCD) guideline for coeliac disease and other gluten-related disorders. United Eur Gastroenterol J. 2019;7:583-613.

3. Gujral N, Freeman HJ, Thomson ABR. Celiac disease: prevalence, diagnosis, pathogenesis and treatment. World J Gastroenterol. 2012;18:6036-59.

4. Husby S, Koletzko S, Korponay-Szabó IR, Mearin ML, Phillips A, Shamir R, et al. European Society for Pediatric Gastroenterology, Hepatology, and Nutrition guidelines for the diagnosis of coeliac disease. J Pediatr Gastroenterol Nutr. 2012;54:136-60.

5. Al-Bawardy B, Codipilly DC, Rubio-Tapia A, Bruining DH, Hansel SL, Murray JA. Celiac disease: a clinical review. Abdom Radiol N Y. 2017;42:351-60.

6. Ludvigsson JF, Leffler DA, Bai JC, Biagi F, Fasano A, Green PHR, et al. The Oslo definitions for coeliac disease and related terms. Gut. 2013;62:43-52.

390 7. Popp A, Kivelä L, Fuchs V, Kurppa K. Diagnosing Celiac Disease: Towards Wide-Scale Screening and Serology-Based Criteria? Gastroenterol Res Pract. 2019;2019:2916024.

8. Stein AC, Liao C, Paski S, Polonsky T, Semrad CE, Kupfer SS. Obesity and Cardiovascular Risk in Adults With Celiac Disease. J Clin Gastroenterol. 2016;50:545-50.

9. Capriati T, Francavilla R, Ferretti F, Castellaneta S, Ancinelli M, Diamanti A. The

395 overweight: a rare presentation of celiac disease. Eur J Clin Nutr. 2016;70:282-4.

10. Aminian A, Andalib A, Ver MR, Corcelles R, Schauer PR, Brethauer SA. Outcomes of Bariatric Surgery in Patients with Inflammatory Bowel Disease. Obes Surg. 2016;26:118690.

11. Deveney CW. Bariatric surgery in severely obese patients with inflammatory bowel

400 disease: a systematic review. Surg Obes Relat Dis Off J Am Soc Bariatr Surg. 2017;13:659_ 60.

12. Dubé C, Rostom A, Sy R, Cranney A, Saloojee N, Garritty C, et al. The prevalence of celiac disease in average-risk and at-risk Western European populations: a systematic review. Gastroenterology. 2005;128:S57-67.

405 13. Andrén Aronsson C, Lee H-S, Hård Af Segerstad EM, Uusitalo U, Yang J, Koletzko S, et al. Association of Gluten Intake During the First 5 Years of Life With Incidence of Celiac Disease Autoimmunity and Celiac Disease Among Children at Increased Risk. JAMA. 2019;322:514-23.

14. Rubio-Tapia A, Hill ID, Kelly CP, Calderwood AH, Murray JA, American College of

410 Gastroenterology. ACG clinical guidelines: diagnosis and management of celiac disease. Am J Gastroenterol. 2013;108:656-76; quiz 677.

15. Holick MF, Binkley NC, Bischoff-Ferrari HA, Gordon CM, Hanley DA, Heaney RP, et al. Evaluation, treatment, and prevention of vitamin D deficiency: an Endocrine Society clinical practice guideline. J Clin Endocrinol Metab. 2011;96:1911-30.

415 16. Zanchetta MB, Longobardi V, Bai JC. Bone and Celiac Disease. Curr Osteoporos Rep. 2016;14:43-8.

17. Caruso R, Pallone F, Stasi E, Romeo S, Monteleone G. Appropriate nutrient supplementation in celiac disease. Ann Med. 2013;45:522-31.

18. Dahele A, Ghosh S. Vitamin B12 deficiency in untreated celiac disease. Am J

420 Gastroenterol. 2001;96:745-50.

19. Kemppainen TA, Kosma VM, Janatuinen EK, Julkunen RJ, Pikkarainen PH, Uusitupa MI. Nutritional status of newly diagnosed celiac disease patients before and after the institution of a celiac disease diet--association with the grade of mucosal villous atrophy. Am 
J Clin Nutr. 1998;67:482-7.

425 20. Valdimarsson T, Toss G, Löfman O, Ström M. Three years' follow-up of bone density in adult coeliac disease: significance of secondary hyperparathyroidism. Scand J Gastroenterol. 2000;35:274-80.

21. Sategna-Guidetti C, Grosso SB, Grosso S, Mengozzi G, Aimo G, Zaccaria T, et al. The effects of 1-year gluten withdrawal on bone mass, bone metabolism and nutritional status in newly-diagnosed adult coeliac disease patients. Aliment Pharmacol Ther. 2000;14:35-43. 22. Wierdsma NJ, van Bokhorst-de van der Schueren MAE, Berkenpas M, Mulder CJJ, van Bodegraven AA. Vitamin and mineral deficiencies are highly prevalent in newly diagnosed celiac disease patients. Nutrients. 2013;5:3975-92.

23. Deora V, Aylward N, Sokoro A, El-Matary W. Serum Vitamins and Minerals at

435 Diagnosis and Follow-up in Children With Celiac Disease. J Pediatr Gastroenterol Nutr. 2017;65:185-9.

24. Matysiak-Budnik T, Fabiani B, Hennequin C, Thieblemont C, Malamut G, Cadiot G, et al. Gastrointestinal lymphomas: French Intergroup clinical practice recommendations for diagnosis, treatment and follow-up (SNFGE, FFCD, GERCOR, UNICANCER, SFCD,

440 SFED, SFRO, SFH). Dig Liver Dis Off J Ital Soc Gastroenterol Ital Assoc Study Liver. 2018;50:124-31.

25. Cellier C, Delabesse E, Helmer C, Patey N, Matuchansky C, Jabri B, et al. Refractory sprue, coeliac disease, and enteropathy-associated T-cell lymphoma. French Coeliac Disease Study Group. Lancet Lond Engl. 2000;356:203-8.

445 26. Ilus T, Kaukinen K, Virta LJ, Pukkala E, Collin P. Incidence of malignancies in diagnosed celiac patients: a population-based estimate. Am J Gastroenterol. 2014;109:1471-7.

27. Howdle PD, Jalal PK, Holmes GKT, Houlston RS. Primary small-bowel malignancy in the UK and its association with coeliac disease. QJM Mon J Assoc Physicians. 2003;96:34553.

450 28. Sharma P, McCarty TR, Lange A, Ngu JN, Njei B. Impact of bariatric surgery on outcomes of patients with celiac disease: a nationwide inpatient sample analysis, 2004-2014. Ann Gastroenterol. 2019;32:73-80.

29. Dickey W, Kearney N. Overweight in celiac disease: prevalence, clinical characteristics, and effect of a gluten-free diet. Am J Gastroenterol. 2006;101:2356-9.

455 30. Singh I, Agnihotri A, Sharma A, Verma AK, Das P, Thakur B, et al. Patients with celiac disease may have normal weight or may even be overweight. Indian J Gastroenterol Off J Indian Soc Gastroenterol. 2016;35:20-4.

31. Cheng J, Brar PS, Lee AR, Green PHR. Body mass index in celiac disease: beneficial effect of a gluten-free diet. J Clin Gastroenterol. 2010;44:267-71.

460 32. Ukkola A, Mäki M, Kurppa K, Collin P, Huhtala H, Kekkonen L, et al. Changes in body mass index on a gluten-free diet in coeliac disease: a nationwide study. Eur J Intern Med. 2012;23:384-8.

33. Tucker E, Rostami K, Prabhakaran S, Al Dulaimi D. Patients with coeliac disease are increasingly overweight or obese on presentation. J Gastrointest Liver Dis JGLD.

$465 \quad 2012 ; 21: 11-5$.

34. Kabbani TA, Goldberg A, Kelly CP, Pallav K, Tariq S, Peer A, et al. Body mass index and the risk of obesity in coeliac disease treated with the gluten-free diet. Aliment Pharmacol Ther. 2012;35:723-9.

35. Reilly NR, Aguilar K, Hassid BG, Cheng J, Defelice AR, Kazlow P, et al. Celiac disease

470 in normal-weight and overweight children: clinical features and growth outcomes following a gluten-free diet. J Pediatr Gastroenterol Nutr. 2011;53:528-31.

36. Sjöström L, Peltonen M, Jacobson P, Sjöström CD, Karason K, Wedel H, et al. Bariatric surgery and long-term cardiovascular events. JAMA. 2012;307:56-65. 
37. Kizy S, Jahansouz C, Downey MC, Hevelone N, Ikramuddin S, Leslie D. National Trends in Bariatric Surgery 2012-2015: Demographics, Procedure Selection, Readmissions, and Cost. Obes Surg. 2017;27:2933-9.

38. Mechanick JI, Apovian C, Brethauer S, Garvey WT, Joffe AM, Kim J, et al. Clinical practice guidelines for the perioperative nutrition, metabolic, and nonsurgical support of patients undergoing bariatric procedures - 2019 update: cosponsored by American

Association of Clinical Endocrinologists/American College of Endocrinology, The Obesity Society, American Society for Metabolic \& Bariatric Surgery, Obesity Medicine Association, and American Society of Anesthesiologists. Surg Obes Relat Dis Off J Am Soc Bariatr Surg. 2020;16:175-247.

39. Buchwald H, Avidor Y, Braunwald E, Jensen MD, Pories W, Fahrbach K, et al. Bariatric surgery: a systematic review and meta-analysis. JAMA. 2004;292:1724-37.

40. Via MA, Mechanick JI. Nutritional and Micronutrient Care of Bariatric Surgery Patients: Current Evidence Update. Curr Obes Rep. 2017;6:286-96.

41. Parrott J, Frank L, Rabena R, Craggs-Dino L, Isom KA, Greiman L. American Society for Metabolic and Bariatric Surgery Integrated Health Nutritional Guidelines for the Surgical

490 Weight Loss Patient 2016 Update: Micronutrients. Surg Obes Relat Dis Off J Am Soc Bariatr Surg. 2017;13:727-41.

42. Busetto L, Dicker D, Azran C, Batterham RL, Farpour-Lambert N, Fried M, et al. Practical Recommendations of the Obesity Management Task Force of the European Association for the Study of Obesity for the Post-Bariatric Surgery Medical Management.

495 Obes Facts. 2017;10:597-632.

43. Freeman LM, Strong AT, Sharma G, Punchai S, Rodriguez JH, Kirby DF, et al. Implications of Celiac Disease Among Patients Undergoing Gastric Bypass. Obes Surg. 2018;28:1546-52.

44. de'Angelis N, Carra MC, Vincenzi F. Gluten-free diet in obese patients with celiac

500 disease: an enemy of the bariatric surgeon? Obes Surg. 2012;22:995-6.

45. Malli CP, Sioulas AD, Emmanouil T, Dimitriadis GD, Triantafyllou K. Endoscopy after bariatric surgery. Ann Gastroenterol. 2016;29:249-57.

46. Pané A, Orois A, Careaga M, Saco A, Ortega E, Vidal J, et al. Clinical onset of celiac disease after duodenal switch: a case report. Eur J Clin Nutr. 2016;70:1078-9.

505 47. Maple JT, Pearson RK, Murray JA, Kelly DG, Lara LF, Fan AC. Silent celiac disease activated by pancreaticoduodenectomy. Dig Dis Sci. 2007;52:2140-4.

48. Cuenca-Abente F, Nachman F, Bai JC. Diagnosis of celiac disease during pre-operative work-up for bariatric surgery. Acta Gastroenterol Latinoam. 2012;42:321-4.

49. Barone M, Della Valle N, Rosania R, Facciorusso A, Trotta A, Cantatore FP, et al. A

510 comparison of the nutritional status between adult celiac patients on a long-term, strictly gluten-free diet and healthy subjects. Eur J Clin Nutr. 2016;70:23-7.

50. Tortora R, Capone P, De Stefano G, Imperatore N, Gerbino N, Donetto S, et al. Metabolic syndrome in patients with coeliac disease on a gluten-free diet. Aliment Pharmacol Ther. 2015;41:352-9. 
Figure legends

Figure 1. Clinical manifestations of celiac disease (gastrointestinal in green) and possible impact of bariatric surgery

520 
Table 1: Frequency and consequences of nutrient deficiencies in celiac disease

\begin{tabular}{|c|c|c|c|}
\hline Absorption site & Nutrient & $\begin{array}{lr}\text { Frequency of } & \text { nutrient } \\
\text { deficiencies } & \text { in } \\
\text { symptomatic } & \text { forms }\end{array}$ & $\begin{array}{l}\text { Main clinical signs of nutrient } \\
\text { deficiency reported }\end{array}$ \\
\hline \multirow[t]{11}{*}{ Duodenum-jejunum } & $\begin{array}{l}\text { Proteins } \\
\text { Carbohydrates } \\
\text { Lipids }\end{array}$ & $60-100 \%$ & $\begin{array}{l}\text { Weight loss, amyotrophy, } \\
\text { hypoalbuminemia, } \\
\text { undernutrition }\end{array}$ \\
\hline & Iron & $40-60 \%$ & Microcytic anemia, hair loss \\
\hline & Calcium & $25-45 \%$ & $\begin{array}{l}\text { Osteopenia, tetany, secondary } \\
\text { hyperparathyroidism }\end{array}$ \\
\hline & Magnesium & $15 \%$ & Muscular cramps, tetany \\
\hline & Vitamin A & $15 \%$ & $\begin{array}{l}\text { Night vision disorders, } \\
\text { infection }\end{array}$ \\
\hline & Vitamin B1 & - & $\begin{array}{l}\text { Peripheral neuropathy, } \\
\text { Wernicke encephalopathy }\end{array}$ \\
\hline & Vitamin B6 & - & Normocytic anemia \\
\hline & Vitamin B9 & $10-90 \%$ & Macrocytic anemia \\
\hline & Vitamin D & $10-60 \%$ & $\begin{array}{l}\text { Osteopenia, tetany, secondary } \\
\text { hyperparathyroidism, bone loss, } \\
\text { osteomalacia }\end{array}$ \\
\hline & Vitamin K & $30 \%$ & Bruising, coagulopathy \\
\hline & Zinc & $30-50 \%$ & $\begin{array}{l}\text { Anorexia, hypoguesia, delayed } \\
\text { growth, impaired wound } \\
\text { healing }\end{array}$ \\
\hline Ileum & Vitamin B12 & $15-40 \%$ & $\begin{array}{l}\text { Macrocytic anemia, peripheral } \\
\text { neuropathy }\end{array}$ \\
\hline
\end{tabular}


Table 2. Prevalence of underweight, normal weight, overweight and obesity in CD as assessed with BMI

\begin{tabular}{|l|l|l|l|l|l|}
\hline Study & $\begin{array}{l}\text { Number of } \\
\text { patients }\end{array}$ & Underweight & Normal & Overweight & Obese \\
\hline $\begin{array}{l}\text { Am J } \\
\text { Gastroenterol } \\
\text { 2006 [38] }\end{array}$ & 371 & $5 \%$ & $57 \%$ & $39 \%$ & $13 \%$ \\
\hline $\begin{array}{l}\text { Indian J } \\
\text { gastroenterol } \\
\text { 2016 [30] }\end{array}$ & 210 & $36 \%$ & $54.8 \%$ & $6.2 \%$ & $2.9 \%$ \\
\hline $\begin{array}{l}\text { J Clin } \\
\text { Gastroenterol }\end{array}$ & 369 & $17.3 \%$ & $60.7 \%$ & $15.2 \%$ & $6.8 \%$ \\
\hline $\begin{array}{l}\text { Eur J Intern } \\
\text { Med 2012 } \\
\text { [32] }\end{array}$ & 698 & $4 \%$ & $57 \%$ & $28 \%$ & $11 \%$ \\
\hline $\begin{array}{l}\text { J } \\
\text { Gastrointestin } \\
\text { Liver Dis } \\
\text { 2012 [33] }\end{array}$ & 187 & $3 \%$ & $53 \%$ & $31 \%$ & $13 \%$ \\
\hline
\end{tabular}


(reported as \% of total cohort).

\begin{tabular}{|c|c|c|c|c|c|c|}
\hline Study & n & $\begin{array}{l}\text { Duration } \\
\text { of GFD } \\
\text { (months) }\end{array}$ & $\begin{array}{l}\text { UW before } \\
\text { GFD }\end{array}$ & $\begin{array}{l}\text { NW before } \\
\text { GFD }\end{array}$ & $\begin{array}{l}\text { OW before } \\
\text { GFD }\end{array}$ & $\begin{array}{l}\text { Obese before } \\
\text { GFD }\end{array}$ \\
\hline $\begin{array}{l}\text { Barone et } \\
\text { al. [49] }\end{array}$ & 39 & 24.3 & $\begin{array}{l}\text { Gained weight: } \\
50 \% \\
\text { Lost } \\
0 \%\end{array}$ & $\begin{array}{ll}\text { Gained weight: } \\
0 \% & \\
\text { Lost } & \text { weight: } \\
0 \% & \end{array}$ & $\begin{array}{l}\text { Gained weight: } \\
0 \% \\
\text { Lost weight: } \\
11 \%\end{array}$ & $\begin{array}{l}\text { Gained weight: } \\
0 \% \\
\text { Lost weight: } \\
0 \%\end{array}$ \\
\hline $\begin{array}{l}\text { Tortora et } \\
\text { al. [50] }\end{array}$ & 98 & 12 & $\begin{array}{l}\text { Gained weight: } \\
60 \% \\
\text { Lost weight: } \\
0 \%\end{array}$ & $\begin{array}{l}\text { Gained weight: } \\
12 \% \\
\text { Lost weight: } \\
0 \%\end{array}$ & $\begin{array}{l}\text { Gained weight: } \\
0 \% \\
\text { Lost weight: } \\
0 \%\end{array}$ & $\begin{array}{l}\text { Gained weight: } \\
0 \% \\
\text { Lost weight: } \\
0 \%\end{array}$ \\
\hline $\begin{array}{l}\text { Kabbani et } \\
\text { al. [34] }\end{array}$ & 679 & 39.5 & $\begin{array}{l}\mathrm{N}=46 \\
\text { Gained } \\
\text { weight*: } \\
52 \% \\
\text { Lost weight**: } \\
2 \%\end{array}$ & $\begin{array}{l}\mathrm{N}=416 \\
\text { Gained } \\
\text { weight*: } \\
21 \% \\
\text { Lost weight**: } \\
5 \%\end{array}$ & $\begin{array}{l}\mathrm{N}=139 \\
\text { Gained } \\
\text { weight*: } \\
22 \% \\
\text { Lost weight**: } \\
18 \%\end{array}$ & $\begin{array}{l}\mathrm{N}=8 \\
\text { Gained } \\
\text { weight*: } \\
22 \% \\
\text { Lost weight**: } \\
23 \%\end{array}$ \\
\hline $\begin{array}{l}\text { Ukkola et } \\
\text { al. [32] }\end{array}$ & 698 & 12 & $\begin{array}{l}\mathrm{N}=28 \\
\text { Gained weight: } \\
69 \% \\
\text { Lost weight: } \\
0 \%\end{array}$ & $\begin{array}{l}\mathrm{N}=398 \\
\text { Gained weight: } \\
38 \% \\
\text { Lost weight: } \\
10 \%\end{array}$ & $\begin{array}{l}\mathrm{N}=195 \\
\text { Gained weight: } \\
22 \% \\
\text { Lost weight: } \\
18 \%\end{array}$ & $\begin{array}{l}\mathrm{N}=77 \\
\text { Gained weight: } \\
16 \% \\
\text { Lost weight: } \\
42 \%\end{array}$ \\
\hline $\begin{array}{l}\text { Cheng et } \\
\text { al. [31] }\end{array}$ & 369 & 33.6 & $\begin{array}{l}\mathrm{N}=64 \\
\text { Gained weight: } \\
66 \% \\
\text { Lost weight: } \\
27 \%\end{array}$ & $\begin{array}{l}\mathrm{N}=224 \\
\text { Gained weight: } \\
58 \% \\
\text { Lost weight: } \\
37 \%\end{array}$ & $\begin{array}{l}\mathrm{N}=56 \\
\text { Gained weight: } \\
40 \% \\
\text { Lost weight: } \\
54 \%\end{array}$ & $\begin{array}{l}\mathrm{N}=25 \\
\text { Gained weight: } \\
18 \% \\
\text { Lost weight: } \\
47 \%\end{array}$ \\
\hline $\begin{array}{ll}\text { Dickey } & \text { et } \\
\text { al. [29] } & \end{array}$ & 188 & 24 & $\begin{array}{l}\mathrm{N}=27 \\
\text { Gained weight: } \\
93 \% \\
\text { Lost weight: } \\
\text { NA }\end{array}$ & $\begin{array}{l}\mathrm{N}=94 \\
\text { Gained weight: } \\
77 \% \\
\text { Lost weight: } \\
\text { NA }\end{array}$ & $\begin{array}{l}\mathrm{N}=67 \\
\text { Gained weight: } \\
82 \% \\
\text { Lost weight: } \\
\text { NA }\end{array}$ & NA \\
\hline
\end{tabular}

$\mathrm{UW}=$ Underweight $\left(\mathrm{BMI}<18.5 \mathrm{~kg} / \mathrm{m}^{2}\right)$

$\mathrm{NW}=$ Normal weight $\left(\mathrm{BMI} 18.6-24.9 \mathrm{~kg} / \mathrm{m}^{2}\right)$

535 OW $=$ Overweight $\left(\right.$ BMI $\left.25-29.9 \mathrm{~kg} / \mathrm{m}^{2}\right)$

$\mathrm{NA}=$ not available

* defined as a BMI increase of 2 points or more; ** defined as a BMI of 2 points or more 